\title{
A self-study of editorial board diversity at Biological Invasions
}

\author{
Sara E. Kuebbing $(\mathbb{D} \cdot$ Matthew A. McCary $\cdot$ Deah Lieurance $\cdot$ Martin A. Nuñez • \\ Mariana C. Chiuffo $\cdot$ Bo Zhang · Hanno Seebens · Daniel Simberloff • \\ Laura A. Meyerson
}

Received: 12 October 2021 / Accepted: 17 October 2021 / Published online: 17 November 2021

(C) The Author(s), under exclusive licence to Springer Nature Switzerland AG 2021

\begin{abstract}
The editorial board of this journal, Biological Invasions, aims to publish research that informs understanding of the patterns and processes of invasions and discussion of relevant policy and conservation issues related to controlling invasions. Because the scope of the journal's interests is global, building an editorial board that represents the demographic, geographic, and topical diversity within the invasion sciences would best serve the journal's readership and reflect the scope of Biological
\end{abstract}

Sara E. Kuebbing and Matthew A. McCary have contributed equally to this piece.

Supplementary Information The online version contains supplementary material available at https://doi.org/10.1007/ s10530-021-02664-8.

S. E. Kuebbing $(\square)$

Department of Biological Sciences, University of

Pittsburgh, Pittsburgh, PA 15260, USA

e-mail: sak267@pitt.edu

S. E. Kuebbing - M. A. McCary

Department of BioSciences, Rice University, Houston,

TX 77005, USA

D. Lieurance

Agronomy Department, University of Florida,

Gainesville, FL 32611, USA

M. A. Nuñez · M. C. Chiuffo

Grupo de Ecología de Invasiones, INIBIOMA,

CONICET, Universidad Nacional del Comahue, Quintral

1250, San Carlos de Bariloche, Argentina
Invasions' global interests. We suspect that an editorial board comprised of members representing the diversity in invasion science can improve data and knowledge on biological invasions and increase participation in Biological Invasions' publication process from more geographic regions and diverse perspectives. To initiate a process of self-reflection and a discussion on editorial representation at Biological Invasions, we are, for the first time, reporting demographic data for the historical and current editorial board membership. As of January 2021, we find skewed representation of certain demographic, geographic, and topical expertise. Over $85 \%$ of editors identify as white, $>70 \%$ speak English as their primary language, $>60 \%$ identify as male, and nearly $50 \%$ of editors are nationals of the United States. The

\footnotetext{
M. A. Nuñez

Department of Biology and Biochemistry, University of Houston, Houston, TX 77204, USA

B. Zhang

Department of Integrative Biology, Oklahoma State

University, Stillwater, OK 74075, USA

H. Seebens

Senckenberg Biodiversity and Climate Research Centre,

Georg-Voigt-Straße 14-16, 60325 Frankfurt, Germany

D. Simberloff

Department of Ecology and Evolutionary Biology,

University of Tennessee, Knoxville, TN 37996, USA
} 
editorship predominantly conducts research in temperate biomes, with most editors considering plants or invertebrates as their organismal expertise. These results highlight geographic and topical areas with uneven expertise that can guide us as we work to diversify the board of Biological Invasions.

Keywords Demographics · Inclusion - Editorial board membership · Equity

\section{Introduction}

Humans have been transporting species around the globe for centuries with this trend increasing in frequency and quantity (Seebens et al. 2017). These actions have led to a proliferation of biological invasions, and today all of Earth's continents and seas harbor non-native species (Turbelin et al. 2017). Nonnative species now occupy every biome and habitat, and many non-natives are highly invasive and damage ecosystem functioning by restructuring native communities (Hejda et al. 2009; Linders et al. 2019), altering interactions (David et al. 2017), or displacing entire populations of native species (Pyšek et al. 2020). Focusing on these trends, Biological Invasions is an international journal with a global scope that publishes "research and synthesis papers on patterns and processes of biological invasions in terrestrial, freshwater, and marine (including brackish) ecosystems. Also of interest are scholarly papers on management and policy issues as they relate to conservation programs and the global amelioration or control of invasions" (https://www.springer.com/journal/10530).

Because of its broad geographic and taxonomic scope, the journal requires a board of editors from diverse geographic locations and with diverse taxonomic expertise to evaluate manuscript submissions. Beyond seeking editorial board members who are diverse in their topical and geographic expertise, there is also merit in editorial boards comprised of editors with diverse demographic identities. This feature seems especially pertinent for ensuring there are editors with expertise to evaluate manuscripts on

\section{A. Meyerson}

Department of Natural Resources Science, University of Rhode Island, Kingston, RI 02881, USA invasive species management and policy, which requires knowledge and experiences to gauge the diversity of social, economic, and cultural factors that should inform conservation and invasive species control programs (Nuñez and Pauchard 2010; Ens et al. 2015). For Biological Invasions, capturing these various dimensions of diversity of the editorial board, of which the authors are members, should help the journal evaluate a wider breadth of research and perspectives on invasions.

Editorial board diversity is also an important component of equity and inclusion in the publishing process. An editorial board comprised of members who reflect the diversity in invasion science will likely improve knowledge and data on biological invasions while also increasing participation from geographic regions not well represented among our published papers (Nuñez et al. 2021) and diversifying perspectives in Biological Invasions' publication process. Editorial board members oversee selection of research articles for publication and invite colleagues to participate in the peerreview process. Because editors are arbiters of a submission's quality, rigor, and impact, they are responsible for ensuring that the publication process is equitable and inclusive to all scholars, independent of a demographic identity. And although editorial boards aspire to achieve an unbiased review process, societal and professional inequities and personal biases can impede objectivity in the editorial process or constrict perspectives on what topics are considered valuable or interesting (Pinholster 2016; Hoppe et al. 2019; Miriti 2020; Pickler et al. 2020; Settles et al. 2020).

Additionally, the demographic identity of editors may influence whom an editor invites to participate in the peer-review process. The journal Functional Ecology found that an editor's gender and current geographic location were positively correlated with the gender and current geographic location of reviewers they invited (Fox et al. 2016). Similar editorial gender biases have been detected at the New Zealand Journal of Ecology (Buckley et al. 2014), journals published by the American Geophysical Union (Lerback and Hanson 2017), and the Frontiers family of journals (Helmer et al. 2017). Another recent selfstudy that included analyses of country-level manuscript reviewer invitations and acceptances from 2003 to 2020 at Biological Invasions found that $47 \%$ of reviewer invitations were extended to reviewers in the United States (Nuñez et al. 2021). Because individual 
editors tend to rely on their own professional networks to source reviewers, one avenue for expanding the demographic range of reviewers is by expanding the demographic range of editors, which can improve expertise, equity, and inclusivity in reviewer participation and publication outcomes (Murray et al. 2019).

Most journals (including Biological Invasions) and their publishing companies do not collect demographic data on authors, reviewers, or editors, in part because of various legal restrictions prohibiting publishers from doing so (e.g., the European General Data Protection Regulation; Voigt and von dem Bussche 2017). It is currently impossible to assess the prevalence or impact of bias in our current editorial process. However, based on the available evidence from other journals (Buckley et al. 2014; Helmer et al. 2017; Fox and Paine 2019; Hagan et al. 2020), we are concerned that the gaps in representation on the editorial board may influence what manuscripts are published, who is invited to review manuscripts, and who is invited to join the editorial board. To begin to address these gaps, we are reporting demographic data for the historical and current editorial board membership for the first time. We present the following two datasets: first, selfreported demographic data of current editors in 2021 from a survey. Second, assigned demographic data (gender and country of employment) of previous editorial board members. We hope these data will counteract the paucity of demographic data in publishing, increase transparency regarding who serves on the editorial board, and begin a process of identifying uneven representation and, if necessary, improving equitability and geographic, topical, and taxonomic coverage in the editorial process.

\section{Methods}

In January 2021, we emailed 144 current editorial board members at Biological Invasions requesting their participation in a voluntary survey (Supplementary Information Appendix 1); the survey response rate was $74 \%$ (107/144). We had two goals: 1$)$ to understand the diversity of the editorial board in terms of expertise, geographic locations, institutional affiliations, and demographic identities, and 2) to source ideas for ways to improve equitability in publishing in the journal, diversify the current editorial board, and decrease potential uneven representation in the editorial process.
The survey consisted of short answer and multiplechoice questions that collected the editor's name, age, nationality, race, gender (female, male, prefer not to say, non-binary, other), primary spoken and written language, secondary spoken and written language(s), year $\mathrm{PhD}$ awarded, country where $\mathrm{PhD}$ was awarded, institution of employment and location, employment position (academic/professor, post-doc, research scientist [e.g., government agency, non-profit], other), year editor joined the board, subdiscipline (evolution, behavioral ecology, molecular genetics, biological control, phylogenetics, animal physiology, systematics, statistics, management, landscape ecology, modeling, evolutionary ecology, ecosystem ecology, bioinformatics, plant physiology, other), taxa of expertise (mammals, birds, fish, reptiles, amphibians, plants, bacteria, viruses, fungi, insects, spiders, aquatic invertebrates, other invertebrates, other), and primary habitat (marine, freshwater aquatic, grassland, forest, desert/arid, wetland, other) and biome (tropical or subtropical, temperate, alpine, arctic or subarctic) where editor works.

Additionally, to evaluate historical changes in gender identity and nation of home institution of the editorial board at Biological Invasions, we used published Biological Invasions volumes to extract the names of editorial board members by year and classified the editors' countries of employment and genders. We classified an editor's gender based on our personal and professional interactions with editorial board members. This dataset reflects board membership between 1999 and 2021 (i.e., Biological Invasions first year to present-day). We illustrate demographic trends of editorial board members using geographic maps, bar plots, and histograms using the R packages "rworldmap" (South 2011) and "ggplot2" (Wickham 2016).

\section{Results}

Geographic distribution

The editorial board at Biological Invasions includes nationals from 21 different countries (Fig. 1, Supplementary Information Appendix 2). Of the 107 respondents, most identify as nationals of the United States (47\%), followed by Canadian (12\%) and British (10\%) nationals (Fig. 1). In total, thirteen percent $(n=14)$ of 


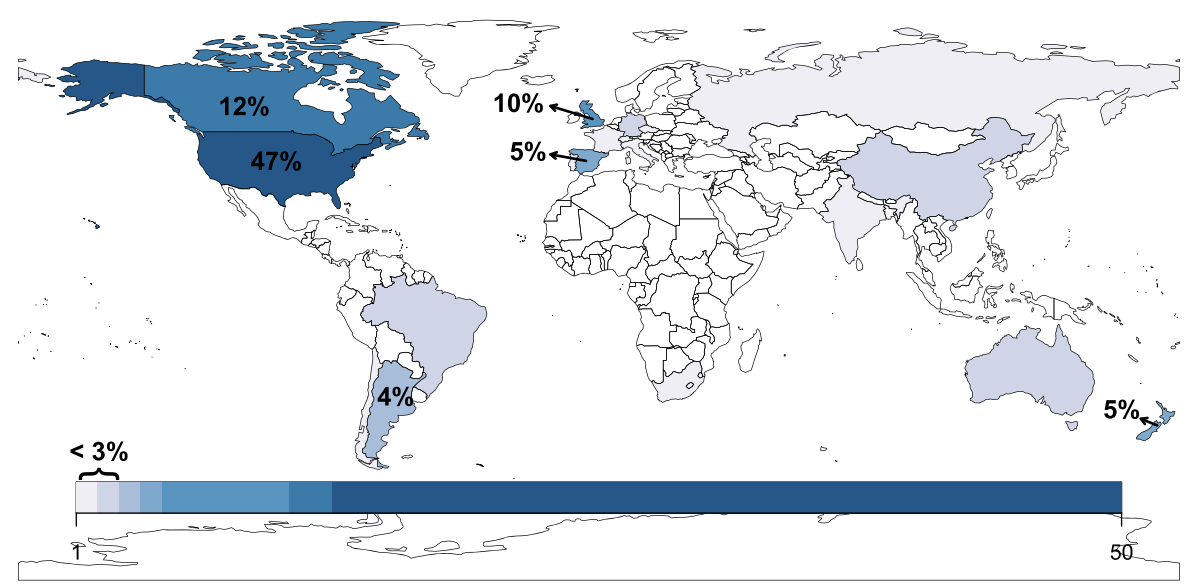

Fig. 1 Editors identifying as nationals of the United States, Canada, and the United Kingdom comprise the top three proportions of 107 Biological Invasions editorial board members in January 2021. The darker shaded colors reflect higher

the editors are nationals of European Union member nations. Except for South Africa, no editors represent the continent of Africa. Only 8\% of the Biological Invasions editors are from South and Central America combined (Fig. 1). Lastly, although southeast Asia is the most populated region in the world, fewer than $4 \%$ of editorial board members represent this region.

Age, race, ethnicity, gender, and languages

The mean age of a Biological Invasions' editor is 48, although editors' ages range from 29 to 78 years (Fig. 2a). Most editors fall within the age range of $40-50$ years $(\mathrm{n}=37)$, followed by $30-40(\mathrm{n}=24)$ and 50-60 years $(\mathrm{n}=21)$, respectively. Ninety-three $(87 \%)$ editors identified as white (Fig. 2b). Asian $(n=7)$ and Latinx/a/o $(n=6)$ ethnicities were the second- and third-most common identities, representing $6.5 \%$ and $5.6 \%$ of Biological Invasions editorial board members, respectively. Indigenous $(n=1)$, Black $(\mathrm{n}=1)$, and multiracial $(\mathrm{n}=1)$ were less common, each representing $<1 \%$ (Fig. 2b). Sixtyseven $(63 \%)$ and $39(36 \%)$ respondents identified as male and female (Fig. 2c), respectively, with one respondent choosing not to answer.

English was the primary language for 77 editors of the 107 survey respondents, $72 \%$ of the editorial board (Fig. 3a). Spanish was the second-most frequently reported primary language (8\%), followed by French (4\%), Portuguese (4\%), and Mandarin (3\%). Editors numbers of board members in that country; nations colored white have no representation of Biological Invasions editors

speak a total of 16 primary and secondary languages (Fig. 3b).

\section{Areas of expertise}

Eighty-four percent of editorial board members consider themselves experts in temperate biomes, followed by tropical (28\%) and sub-tropical (27\%) biomes (Fig. 4a). Cold biomes are less represented on the board, with $\sim 15 \%$ of the editors reporting expertise in arctic, subarctic, and alpine ecosystems combined. Forest $(28 \%)$ and freshwater $(23 \%)$ habitats are the most studied by the editorial board; grassland (16\%) and marine habitats (11\%) were the third- and fourth-most popular areas of board members' expertise (Fig. 4b). Very few editorial board members reported working in mountain $(<1 \%)$ or shrubland $(<1 \%)$ habitats (Fig. $4 b)$.

Although many subdisciplines of expertise are represented on the editorial board, community ecology (11\%) and ecosystem ecology (10\%) were the most common (Fig. 5a). The subdisciplines of animal physiology, landscape ecology, molecular ecology, and urban ecology were less represented, together comprising only $8 \%$ of the editorial board's area of expertise (Fig. 5a). Plants (45\%), terrestrial insects (25\%), and aquatic invertebrates $(24 \%)$ are the most common organisms studied by editorial board members (Fig. 5b). Parasites, humans, and plankton/zooplankton are less studied organisms, each 

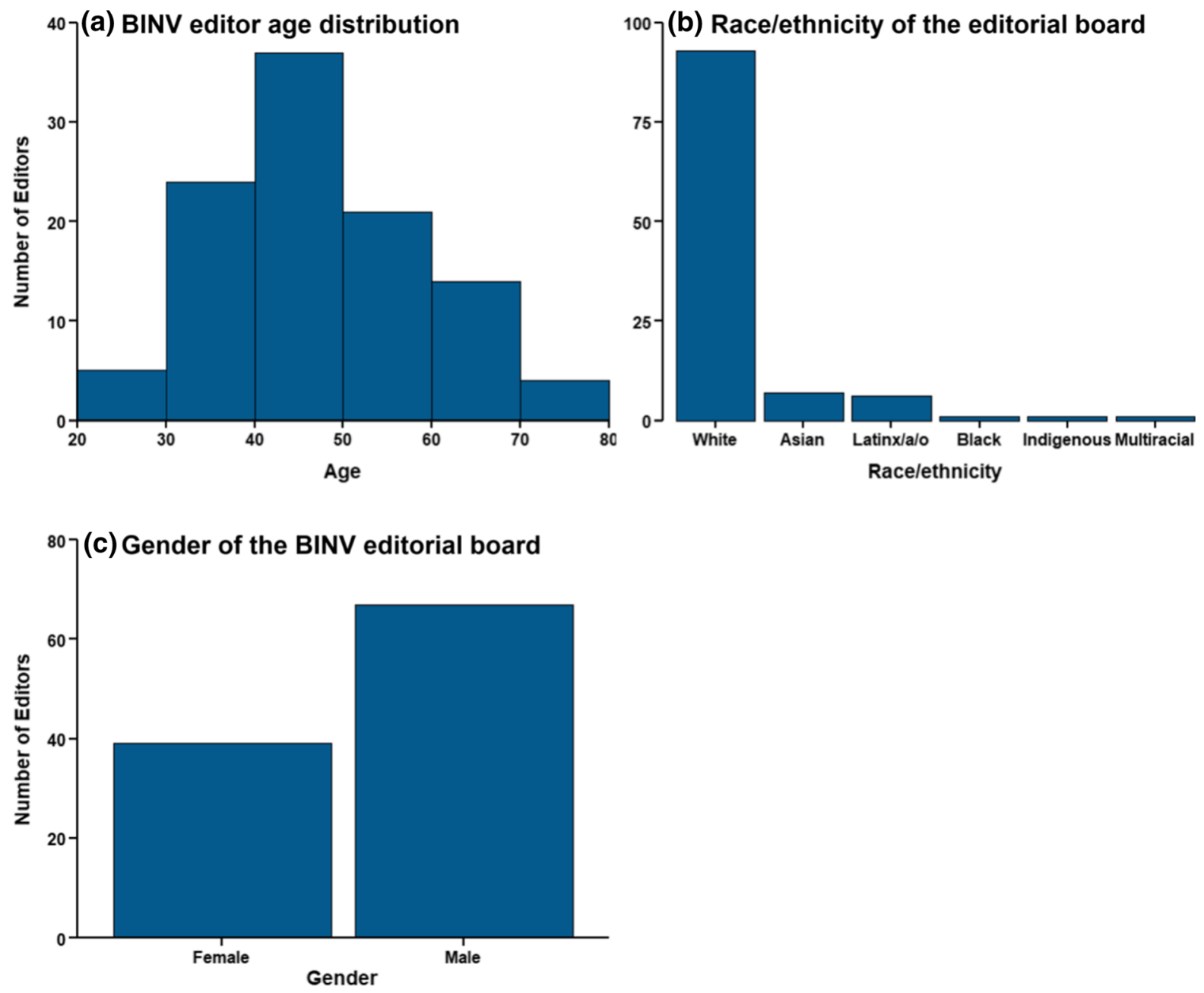

Fig. 2 Self-reported age (a), race/ethnicity (b), and gender (c) identities of 107 editorial board members at Biological Invasions from a January 2021 survey. For reporting of race, ethnicity, and gender, editors had multiple-choice and write-in options

constituting $\sim 2 \%$ of the board's organismal expertise.

Educational background and time on editorial board

The mean number of years since the $\mathrm{PhD}$ was awarded is 18 years, with most editors earning their doctoral degree in the last 20 years (Fig. 6a). Eighty-eight $(82 \%)$ of the 107 survey respondents joined the editorial board in the past 10 years (Fig. 6b), indicating that many board members are relatively recent additions (average time since joining the board is 6 years). Five board members have served on the board since the journal's founding in 1999. Most editorial board members are university faculty (70\%), followed by research scientists (20\%) and postdoctoral scholars (8\%) (Fig. 6c).

Changes in the Biological Invasions editorial board through time

At the inception of Biological Invasions in 1999, only three $(15 \%)$ of the 20 editorial board members were women (Fig. 7). An increase in representation among women began in 2003 (20\%), with this trend increasing to present-day (36\% women in 2021) (Fig. 7). It is also worth noting the sharp increase in the total number of editors at Biological Invasions starting in 2010 (Fig. 7). 

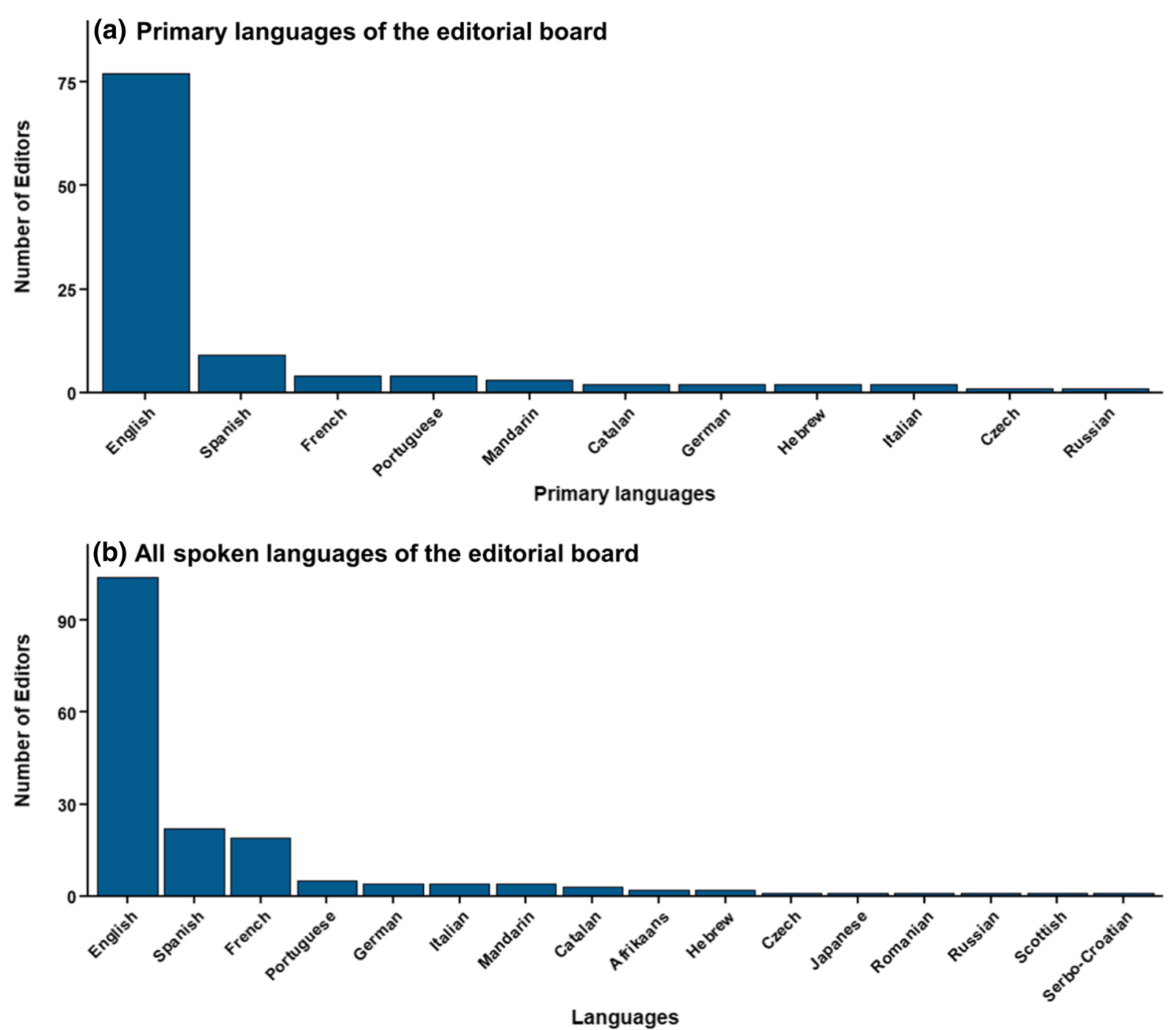

Fig. 3 Self-reported primary language (a) of 107 Biological Invasions editorial board members. Board members reported proficiency in a total of 16 languages (b)

Similar to the trends found for gender, there is an expansion in the number of countries represented by the Biological Invasions editorial board (Fig. 8). In 1999, editors worked at institutions found in only 10 countries. By 2021, the number of countries represented has increased 2.5-fold $(\mathrm{n}=25)$. United States' institutions have employed the largest proportion of editors over the 21-year timespan, with $35-56 \%$ of the board members working in the United States (Fig. 8). Canada had the biggest expansion of Biological Invasions editors, with no Canadian editors in 1999 and $13(9 \%)$ by 2021.

\section{Discussion}

This is the first quantification of the topical, geographic, and demographic makeup of Biological Invasions' editorial board. The survey results indicate the editorial board is skewed towards members of certain demographic and geographic identities, but there has been an increase in gender and geographic representation since the journal's first issue in 1999. The journal's first editorial board, established in 1999 with James T. Carlton as Editor-in-Chief, consisted of 20 editors who worked at institutions in 10 different nations, all were white, and only 3 were women. 

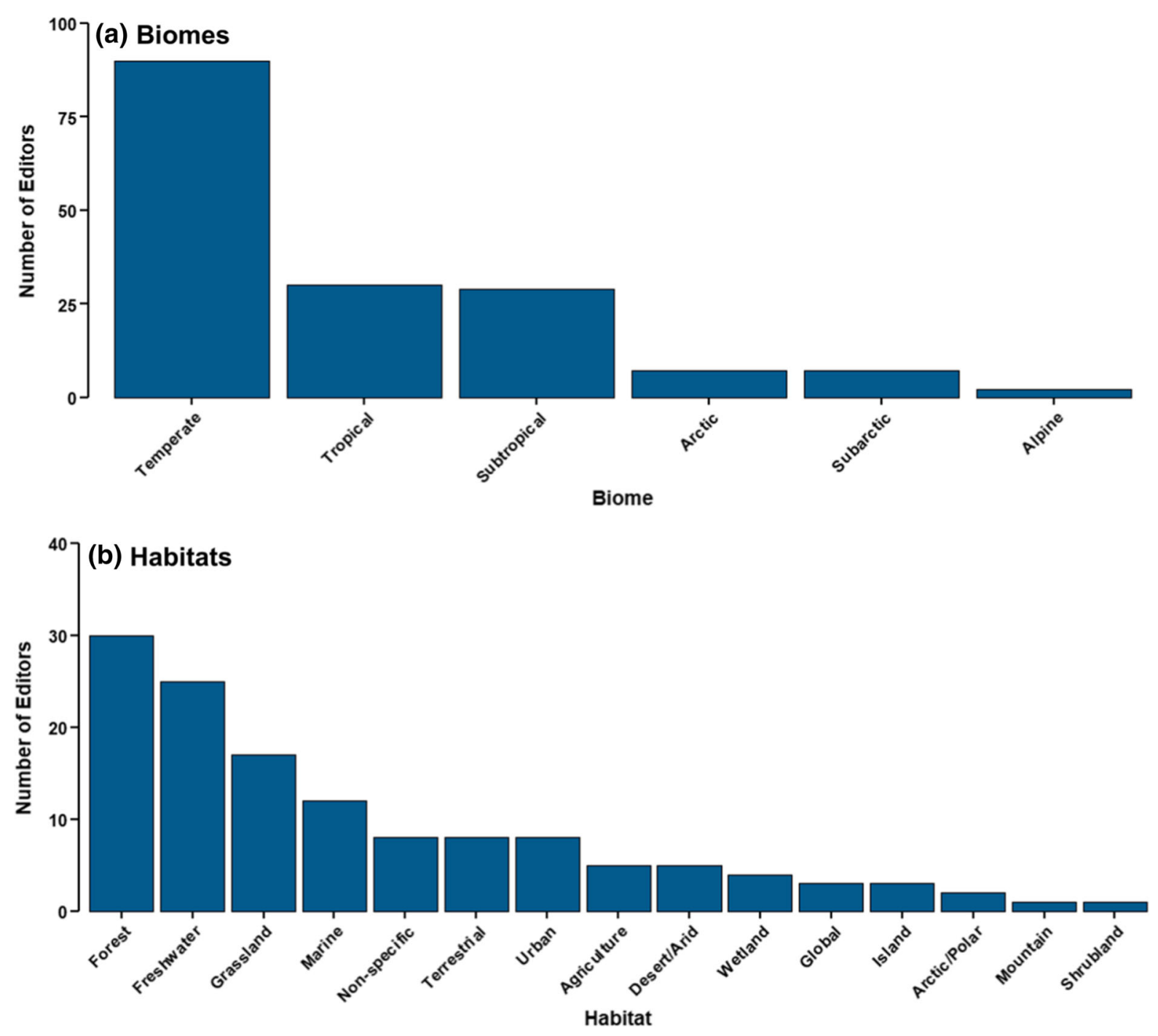

Fig. 4 Editorial board members at Biological Invasions conduct research in all major biomes (a) and many different habitats (b), but with greater representation in temperate biomes and forest, freshwater, and grassland habitats

Today, the board is composed of 148 editors (four editors joined the board since we conducted the survey) representing at least 21 different nationalities working at institutions in 25 different nations. The proportion of female editors has doubled to $36 \%$ of the editorial board. These changes in the overall board's demographics reflect concerted efforts by current and past Editors-in-Chiefs to diversify the gender and geographic representation of editors. While editors represent all continents but Antarctica, the distribution is heavily weighted to those working in the United States, Canada, and the United Kingdom.
English is the primary language of $\sim 70 \%$ of editors, over $60 \%$ identify as male, and $42 \%$ of editors are nationals of the United States. In some respects, this editorial board demographic distribution at Biological Invasions mirrors the uneven representation of demographic identities of the global research pool. The UNESCO Science Report 2021 estimates that female researchers comprise approximately one-third of the world's researchers (Bello et al. 2021), matching the gender proportions of the editorial board. However, in other aspects, the demography of the board does not reflect relative global proportions of researchers. In 2018, the European Union (23.5\%; 

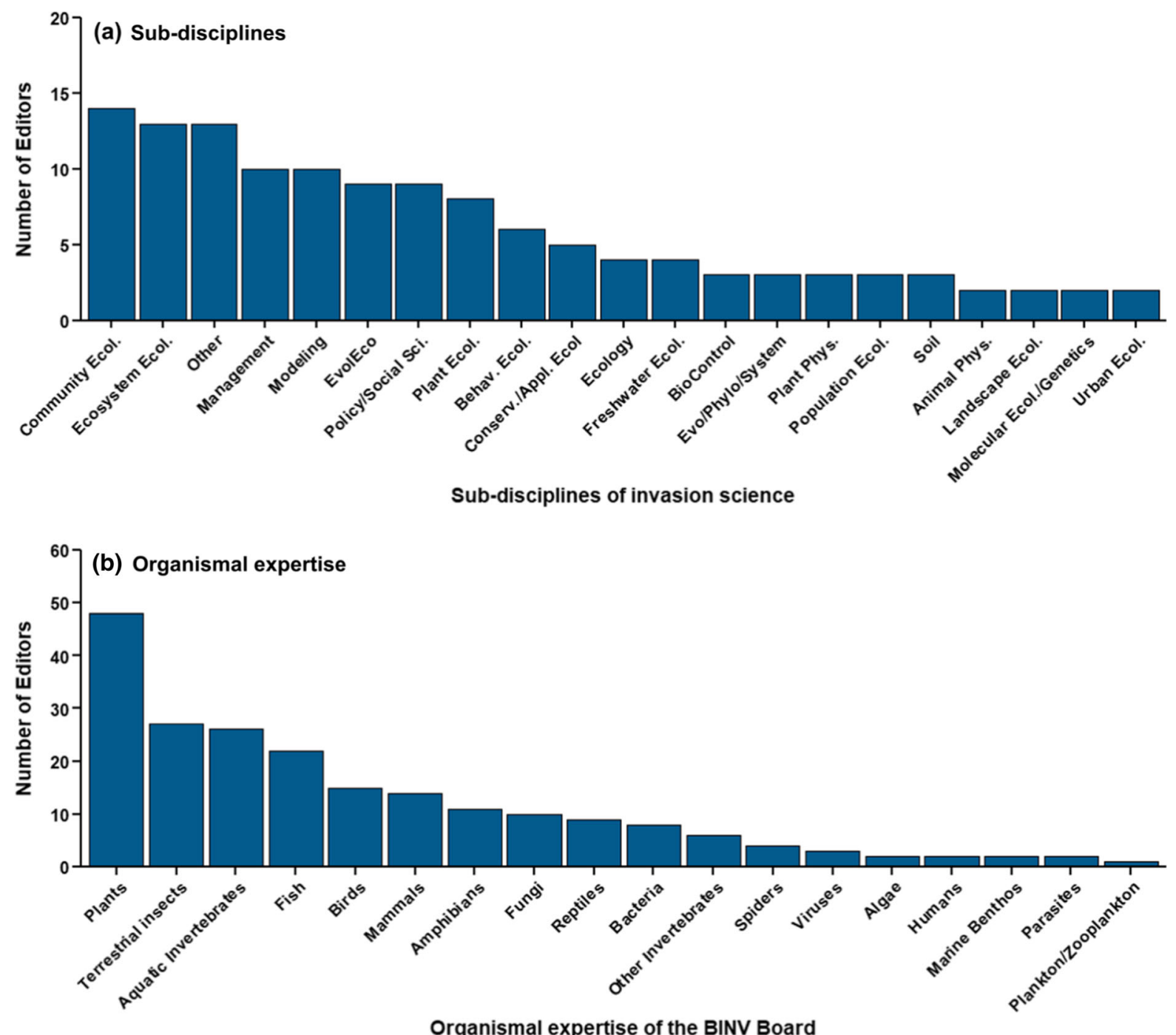

Fig. 5 Bar plots illustrating the a subdisciplines of invasion science and $\mathbf{b}$ the organismal expertise of 107 Biological Invasions editorial board members in January 2021

including the United Kingdom at this time), China $(21.1 \%)$ and the United States $(16.2 \%)$ comprised the three largest shares of global researchers (UNESCO 2021). The top four regions represented by board members were the United States (47\%), the European Union (12\%), Canada (13\%) and the United Kingdom (10\%). Among board members from the United States $(n=50)$, disparities exist between the demographic identities and recent doctorate recipients from institutions in the United States. Of United States nationals on the board, $94 \%$ identified as white and $61 \%$ as male. In contrast, the National Center for Science and Engineering Statistics reported that, in 2019, only $68 \%$ of United States citizens or permanent residents who received doctorates in the Life Sciences from institutions in the United States identified as white and 44\% identified as male (NCSES, https://ncsesdate.nsf.gov/ home). Unfortunately, limited and inconsistent data reporting on demographic identities and subdiscipline expertise of researchers (UNESCEO 2021) makes it impossible to evaluate whether the demographics of Biological Invasions editorial board broadly represent the pool of potential researchers who have expertise in invasion science worldwide.

Collecting and publishing data on the expertise and demographic identity of the current editorial board 

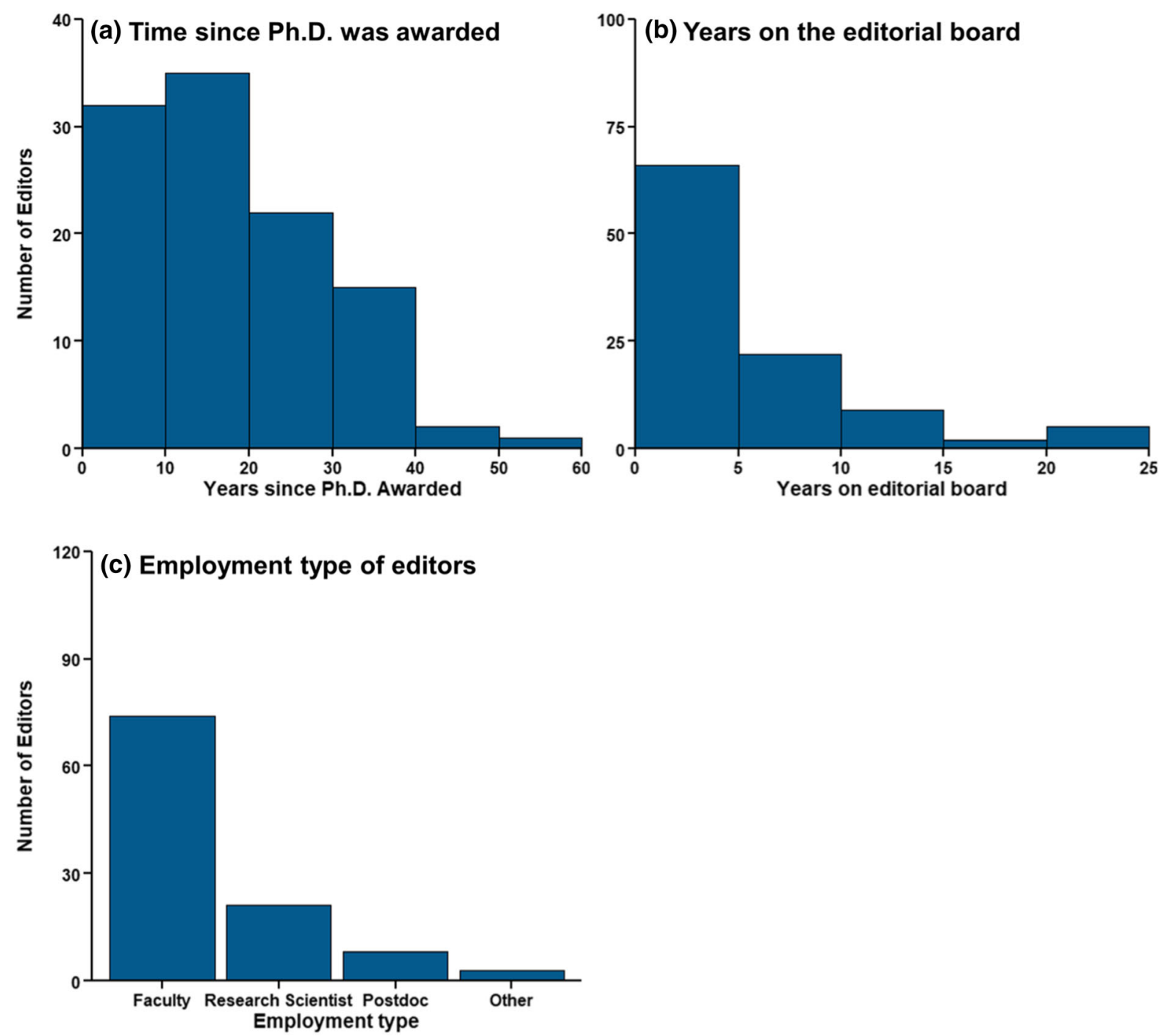

Fig. 6 Histograms showing a years since the $\mathrm{PhD}$ was awarded and $\mathbf{b}$ number of years on the editorial board for 107 Biological Invasions editorial board members in January 2021. The majority of editors are employed as faculty at universities (c)

could help identify areas where we need more editorial expertise. For example, the editorship largely conducts research in temperate biomes, while we currently have fewer editors with self-reported expertise in tropical, subtropical, alpine, and arctic biomes. These latter regions are predicted to see accelerating invasion rates in the future (Lonsdale 1999; Seebens et al. 2015; Wasowicz et al. 2020; Nuñez et al. 2021), and broadening expertise of current board members may be warranted in anticipation of increased manuscript submissions from these regions.

Our survey of current editorial board members also reflects signs of changing demographics of editors at different career stages. Roughly one-third of the current editors obtained their $\mathrm{PhD}$ in the past decade, and substantially more of these early-career editors identified as female $(61 \%)$ relative to current editors who received their $\mathrm{PhDs}$ prior to 2010 ( 25\%). However, we did not find changes in the racial or ethnic identities of the current board based on year since PhD. Of current board members who earned their $\mathrm{PhD}$ since 2010, $\sim 86 \%$ identified as white, similar to the proportion of current board members who identified as white and earned their $\mathrm{PhD}$ before 2010 ( 87\%). Because the context and understanding of the terms 'race' or 'ethnicity' differ among 


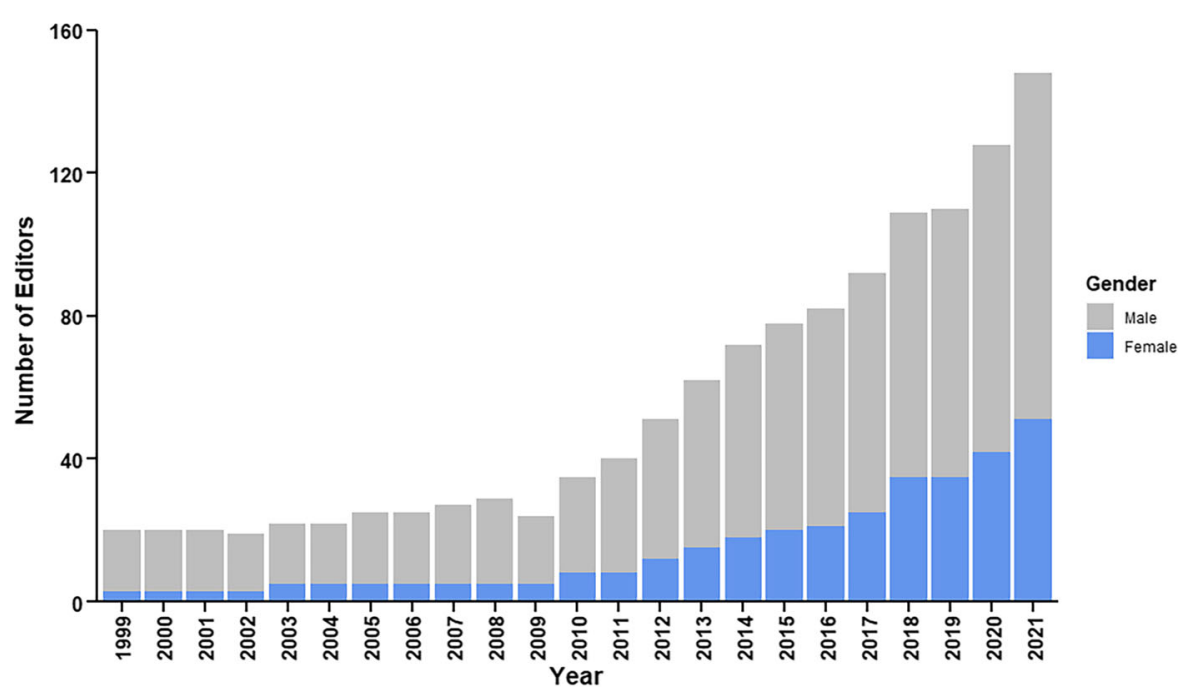

Fig. 7 Bar plots showing changes in editor gender over time at Biological Invasions, which was started in 1999

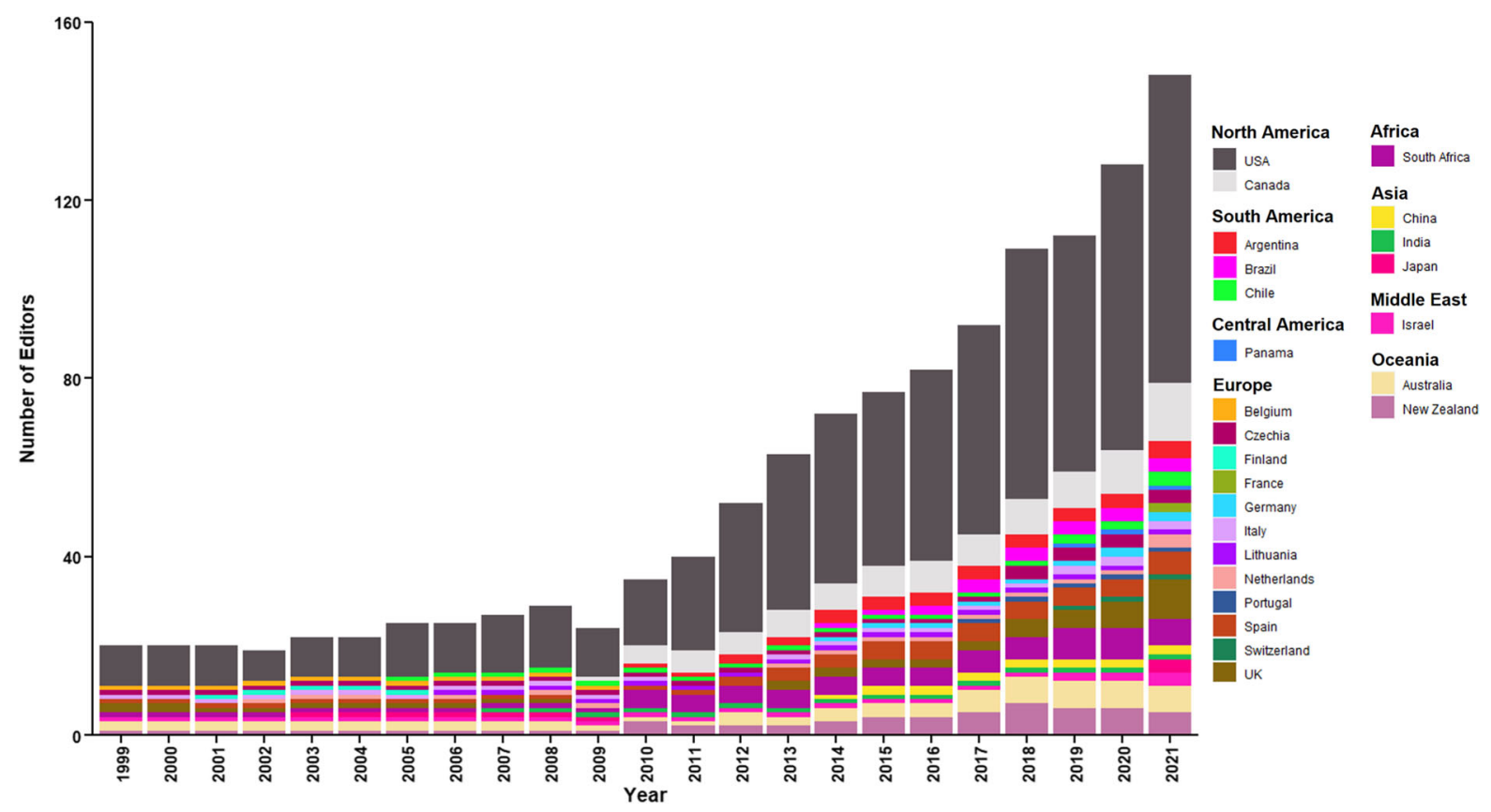

Fig. 8 The countries represented by editorial board members at Biological Invasions from 1999 to 2021

countries and cultures, we note that these are selfreported racial identities and individual editors may have used different personal definitions when answering this question.

\section{Concluding thoughts}

This survey and analysis were motivated by a wider discussion of how academic journals can be more inclusive and reduce identity biases that create barriers for some researchers to participate equally in the 
publication process (Buckley et al. 2014; Pinholster 2016; Edwards 2018; Mindt et al. 2018; Fox and Paine 2019; Müller 2019; Araújo and Shideler 2019; Harris 2019; Day et al. 2020; Hagan et al. 2020). Additionally, including diverse perspectives is crucial for advancing knowledge (Manlove and Belou 2018; Nuñez et al. 2021; Yitbarek et al. 2021). In the field of biological invasions, diversity of views and ideas is particularly necessary as the consequences of invasions often differ among regions and environmental contexts (Freestone et al. 2013; Sapsford et al. 2020; Stotz et al. 2016; Zarnetske et al. 2013). This manuscript is a small step towards answering bigger questions about inclusion and equity at Biological Invasions, which include whether disparities exist in the publication rates of authors based on their demographic identities, and whether the identities of the current editorial board influence whom we invite to participate in the editorial process as both editors and reviewers. Answering questions about where potential disparities exist would allow us then to ask why those disparities exist and how we can adapt procedures to reduce them.

Yet, in the many discussions that surrounded the writing of this manuscript, we found ourselves continually limited by the availability of data on the demographic identities of researchers who submit manuscripts to the journal and the reviewers who assess them. This paucity of data is not a problem unique to Biological Invasions and has led leading journals and publishers to call for developing ways to collect these data fairly, transparently, and uniformly (Pinholster 2016). This manuscript is therefore limited in its scope to assessing the demographics of the editorial board.

We hope that this publication sets a precedent of more transparency about the editorial board membership at Biological Invasions and provides information on the current areas of expertise of the board that could guide future invitations to potential new editors. There will be value in repeating this self-study-adapting and adding questions as necessary to capture areas of diversity we missed during this survey-at regular intervals to track changes in editorial board expertise and demography. Finally, we also hope this study will stimulate a larger discussion among our colleagues who study invasion science about equity and inclusion in our discipline. We believe that talking about equity and inclusion in the publication process will allow the journal to continue to produce and publish rigorous science on invasion science as well as policy and management publications that can improve the control and amelioration of invasions in all regions of the globe.

Acknowledgements We thank the members of the editorial board of Biological Invasions for participating in the board survey and for ongoing discussions. We thank Janet Slobodien for assisting us in understanding current publishing policies.

Data availability statement The full datasets generated for the current study are not publicly available to protect the privacy of individuals on the board. We present aggregated summary data of survey questions in the present article and its supplementary information files.

\section{Declarations}

Conflict of interests The authors declare that they have no Conflict of Interests.

Consent to participate All authors consent to participate in this manuscript.

Consent for publication All authors consent in publishing this manuscript.

\section{References}

Araújo R, Shideler G (2019) Cultural and geographical representation in the editorial boards of aquatic science journals. Sci Ed 42:121-124

Bello A, Blowers T, Schneegans S, Straza T (2021) To be smart, the digital revolution will need to be inclusive. In UNESCO Science Report: the Race Against Time for Smarter Development. Straza T, Schneegans S, Lewis J (Eds) UNESCO Publishing. pp.109-135

Buckley HL, Sciligo AR, Adair KL, Case BS, Monks JM (2014) Is there gender bias in reviewer selection and publication success rates for the New Zealand Journal of Ecology? N Z J Ecol 38:335-339

David P, Thebault E, Anneville O, Duyck PF, Chapuis E, Loeuille N (2017) Impacts of invasive species on food webs: a review of empirical data. Adv Ecol Res 56:1-60

Day AE, Corbett P, Boyle J (2020) Is there a gender gap in chemical sciences scholarly communication? Chem Sci 11:2277-2301

Edwards HA, Schroeder J, Dugdale HL (2018) Gender differences in authorships are not associated with publication bias in an evolutionary journal. PLOS One 13:e0201725

Ens E, Fisher J, Costello O (2015) Indigenous people and invasive species: perceptions, management, challenges and uses. IUCN Commission on Ecosystem Management Community Report 
Fox CW, Paine CE (2019) Gender differences in peer review outcomes and manuscript impact at six journals of ecology and evolution. Ecol Evol 9:3599-3619

Fox CW, Burns CS, Meyer JA (2016) Editor and reviewer gender influence the peer review process but not peer review outcomes at an ecology journal. Fun Ecol 30:140-153

Freestone AL, Ruiz GM, Torchin ME (2013) Stronger biotic resistance in tropics relative to temperate zone: effects of predation on marine invasion dynamics. Ecology 94:1370-1377

Hagan AK, Topçuoğlu BD, Gregory ME, Barton HA, Schloss PD (2020) Women are underrepresented and receive differential outcomes at asm journals: a six-year retrospective analysis. Mbio 11:6

Harris S (2019) Toward global equity in scholarly communication. Sci Ed 42:114-116

Hejda M, Pyšek P, Jarošík V (2009) Impact of invasive plants on the species richness, diversity and composition of invaded communities. J Ecol 97:393-403

Helmer M, Schottdorf M, Neef A, Battaglia D (2017) Gender bias in scholarly peer review. Elife 6:e21718

Hoppe TA, Litovitz A, Willis KA, Meseroll RA, Perkins MJ, Hutchins BI, Davis AF, Lauer MS, Valantine HA, Anderson JM, Santangelo GM (2019) Topic choice contributes to the lower rate of NIH awards to African-American/black scientists. Sci Adv 5:eaaw7238

Lerback J, Hanson B (2017) Journals invite too few women to referee. Nature 541:455-458

Linders TEW, Schaffner U, Eschen R, Abebe A, Choge SK, Nigatu L, Mbaabu PR, Shiferaw H, Allan E (2019) Direct and indirect effects of invasive species: biodiversity loss is a major mechanism by which an invasive tree affects ecosystem functioning. J Ecol 107:2660-2672

Lonsdale WM (1999) Global patterns of plant invasions and the concept of invasibility. Ecology 80:1522-1536

Manlove KR, Belou RM (2018) Authors and editors assort on gender and geography in high-rank ecological publications. PLoS ONE 13:e0192481

Mindt MR, Hilsabeck RC, Olsen JP, Savin MJ, Crook CL, Suchy Y (2018) Advancing science through diversity and inclusion in the editorial process: a case study. Sci Ed 41:93-96

Miriti MN (2020) The elephant in the room: race and STEM diversity. Bioscience 70:237-242

Müller UK (2019) Editorial: Science needs an inclusive and transparent publication process-how Integrative and Comparative Biology works toward this aim. Integr Comp Biol 59:1445-1450

Murray D, Siler K, Larivière V, Chan WM, Collings AM, Raymond J, Sugimoto CR (2019) Author-reviewer homophily in peer review. BioRxiv. https://doi.org/10.1101/400515

Nuñez MA, Chiuffo MC, Seebens H, Kuebbing S, McCary M, Lieurance D, Zhang B, Simberloff D, Meyerson LA (2021) Two decades of data reveal that Biological Invasions needs to increase participation beyone North America, Europe, and Australasia. Biol Invasions. https://doi.org/10.1007/ s10530-021-02666-6

Nuñez MA, Pauchard A (2010) Biological invasions in developing and developed countries: does one model fit all? Biol Invasions 12:707-714

Pickler RH, Munro CL, Likis FE (2020) Addressing racism in editorial practices. Nurse Author Ed 3:5
Pinholster G (2016) Journals and funders confront implicit bias in peer review. Science 352:1067-1068

Pyšek P, Hulme PE, Simberloff D, Bacher S, Blackburn TM, Carlton JT, Dawson W, Essl F, Foxcraft LC, Genovesi P, Jeschke JM, Kühn I, Liebhold AM, Mandrak NE, Meyerson LA, Pauchard A, Pergl J, Roy HE, Seebens H, van Kleunen M, Vilà M, Wingfield MJ, Richardson DM (2020) Scientists' warning on invasive alien species. Biol Rev 95:1511-1534

Sapsford SJ, Brandt AJ, Davis KT, Peralta G, Dickie IA, Gibson RD, Green JL, Hulme PE, Nuñez MA, Orwin KH (2020) Towards a framework for understanding the context-dependence of impacts of non-native tree species. Funct Ecol 34:944-955

Seebens H, Essl F, Dawson W, Fuentes N, Moser D, Pergl J, Pyšek P, van Kleunen M, Weber E, Winter M, Blasius B (2015) Global trade will accelerate plant invasions in emerging economies under climate change. Glob Change Biol 21:4128-4140

Seebens H, Blackburn TM, Dyer EE et al (2017) No saturation in the accumulation of alien species worldwide. Nat Comms 8:14435

Settles IH, Jones MK, Buchanan NT, Dotson K (2020) Epistemic exclusion: scholar(ly) devaluation that marginalizes faculty of color. J Divers High Educ. https://doi.org/10. 1037/dhe0000174

South A (2011) rworldmap: a new R package for mapping global data. R J 3:35-43

Stotz GC, Pec GJ, Cahill JF (2016) Is biotic resistance to invaders dependent upon local environmental conditions or primary productivity? A meta-analysis. Basic Appl Ecol 17:377-387

Turbelin AJ, Malamud BD, Francis RA (2017) Mapping the global state of invasive alien species: patterns of invasion and policy responses. Glob Ecol Biogeogr 26:78-92

UNESCO (2021) UNESCO Science Report: the race against time for smarter development. S. Schneegans, T Straza, J Lewis (Eds.). UNESCO Publishing, Paris, France

Voigt P, von dem Bussche A (2017) The EU general data protection regulation (GDPR). Springer International Publishing AG. Cham, Switzerland. p. 383

Wasowicz P, Sennikov AN, Westergaard KB, Spellman K, Carlson M, Gillespie LJ, Saarela JM, Seefeldt SS, Bennett B, Bay C, Ickert-Bond S, Väre H (2020) Non-native vascular flora of the Arctic: taxonomic richness, distribution and pathways. Ambio 49:693-703

Wickham H (2016) ggplot2: elegant graphics for data analysis. Springer-Verlag, New York, USA. https://ggplot2.tidyverse. org

Yitbarek S, Bailey K, Tyler S, Strickland J, McCary M, Harris N (2021) Inclusive sustainability approaches in commonpool resources from the perspective of Blackologists. Bioscience 71(7):741-749

Zarnetske PL, Gouhier TC, Hacker SD, Seabloom EW, Bokil VA (2013) Indirect effects and facilitation among native and non-native species promote invasion success along an environmental stress gradient. J Ecol 101:905-915

Publisher's Note Springer Nature remains neutral with regard to jurisdictional claims in published maps and institutional affiliations. 